1997-6

\title{
Changes in network characteristics and HIV risk behavior among injection drug users
}

John P. Hoffmann

Brigham Young University - Provo, john_hoffmann@byu.edu

\section{S. Susan Su}

National Opinion Research Center

Alfred Pach

Emory University

Follow this and additional works at: https://scholarsarchive.byu.edu/facpub

Part of the Medicine and Health Commons, and the Social Control, Law, Crime, and Deviance

Commons

\section{Original Publication Citation}

Hoffmann, John P., S. Susan Su, and Alfred Pach. 1997. "Changes in Network Characteristics and HIV Risk Behavior among Injection Drug Users." Drug and Alcohol Dependence 46(1-2):41-51.

\section{BYU ScholarsArchive Citation}

Hoffmann, John P.; Su, S. Susan; and Pach, Alfred, "Changes in network characteristics and HIV risk behavior among injection drug users" (1997). Faculty Publications. 3952.

https://scholarsarchive.byu.edu/facpub/3952

This Peer-Reviewed Article is brought to you for free and open access by BYU ScholarsArchive. It has been accepted for inclusion in Faculty Publications by an authorized administrator of BYU ScholarsArchive. For more information, please contact ellen_amatangelo@byu.edu. 


\title{
Changes in network characteristics and HIV risk behavior among injection drug users
}

\author{
John P. Hoffmann ${ }^{\mathrm{a}, *}$, S. Susan Su ${ }^{\mathrm{a}}$, Alfred Pach ${ }^{\mathrm{b}}$ \\ a National Opinion Research Center, University of Chicago, Washington Office, 1350 Connecticut Avenue, Suite 500, Washington, \\ DC 20036, USA \\ ${ }^{\mathrm{b}}$ Department of Family and Preventive Medicine, Emory University, USA
}

Received 14 October 1996; accepted 28 February 1997

\begin{abstract}
Studies indicate that HIV risk behaviors vary greatly among injection drug users (IDUs). The source of such variation is often ascribed to individual differences, but much of it is due to how IDUs are grouped into social networks. Nevertheless, given the turbulent and uncertain lives led by many IDUs, it would not be surprising if their social networks changed substantially over time. We used data from a study of the social networks of IDUs in Chicago and Washington, DC, to examine changes in individual behavior and network characteristics over time. The results indicated few changes in standard network measures, such as density of ties or network size, over time. However, specific network change measures, that is, indicators of movement into and out of networks, showed significant movement of network members over time. Moreover, movement of members into a network significantly predicted a higher likelihood of risky injection drug use over time. We suggest that these movements are indicative of a lack of a stable resource base among IDU networks. (C) 1997 Elsevier Science Ireland Ltd.
\end{abstract}

Keywords: Injection drug user; HIV risk behaviors; Social networks; Network changes

\section{Introduction}

The composition of HIV risk groups in the US has been shifting from men who have sex with men to injection drug users and their sexual partners. Injection drug users (IDUs) represent the second most frequent exposure category among persons with AIDS in the US, with about one-quarter of the cumulative AIDS cases consisting of IDUs. Moreover, in several major epicenters, such as Chicago and Washington, DC, the proportion of IDUs among all AIDS patients has increased from about one-fifth in 1988 to over one-third in 1994 (AIDS Surveillance and Epidemiology Programs, 1994; Division of HIV/AIDS Epidemiology, 1994).

Research on sexual behavior and injection drug use,

* Corresponding author. and the HIV risks that accompany them, has begun to recognize the importance of raising the level of abstraction beyond the individual. Many of the theories used to explain these behaviors, such as economically-based choice theories (sexual behavior) or particular personality theories (drug use), focus principally on the individual, and how specific individual attributes such as perceived benefits or lack of self-control affect behavior (e.g. Gibson et al., 1991; Nyamathi et al., 1995; Petraitis et al., 1995). Several studies, however, have shown the serious limitations of these theoretical approaches. Sexual behavior and drug use tend to occur within particular social groups, and are therefore conditioned by interactions among individuals (Laumann et al., 1994). Studies of IDUs, for example, demonstrate clearly that injection occurs often in group settings and that sharing drugs and injection paraphernalia is common (Bourgois, 1995; Hanson et al., 1985; Inciardi and Page, 1991; Koester, 1995; Magura et al., 1991; Neaigus 
et al., 1994; Page, 1990). These studies have shifted attention from the individual to dyadic and triadic interactions that affect HIV risk behaviors (MacQueen, 1994).

However, recent research suggests that a focus on dyads and triads fails to capture the true social and interactive qualities that characterize injection drug use and HIV risk behaviors. Research on how IDUs are organized into social networks (sets of actors and their interrelationships; Wasserman and Faust, 1994) has provided essential details about the transmission of HIV across risk groups. Klovdahl et al. (1994), for instance, showed that the average distance (number of interpersonal paths needed to establish a risk link) from HIV positive persons in Colorado Springs to everyone else in their sampled network of over 600 individuals was about three. Therefore, concentrating only on dyadic structures fails to reveal the true risk of infection in a network of individuals. Wallace (1991), focusing on macro-level processes, suggested that the structure of drug using networks, coupled with HIV prevalence within and across these networks, determines the rate of spread of HIV infection across communities.

Social network studies of IDUs also demonstrate that various group-level or network-level variables exert a significant influence on risk behaviors among IDUs, even when controlling for the effects of individual- or dyadic-level characteristics. In a social network study of IDUs in Baltimore, for example, Latkin et al. (1995a) found that network density (the proportion of network members who know each other) and the size of the drug network significantly predicted frequency of injection, even when controlling for the effects of age, gender, education and years of injecting. IDUs residing in more dense networks or larger drug networks injected more frequently than those in less dense or smaller networks (Trotter et al., 1995).

Neaigus et al. (1994), in a study of IDUs from various sections of New York city, discovered that the proportion of friendship contact ties that an IDU has with non-IDUs predicts less risky injection behavior (less direct and indirect sharing of equipment). In a further analysis of social network data that focused on IDUs from Brooklyn, Neaigus et al. (1995) determined that IDUs who report being in networks with high frequency injectors, or in networks with members who injected in shooting galleries, were more likely to be HIV positive. Moreover, women who reported older injectors in their networks were also more likely to be HIV positive. These various studies demonstrate that raising the level of abstraction from individuals to networks provides important information about risky interactions within and among groups of IDUs, and how these interactions affect the spread of HIV across populations (Blower and Medley, 1992; MacQueen, 1994; Morris, 1993; Rothenberg et al., 1995).

\subsection{The dynamic nature of social networks}

An important limitation of research on social networks of IDUs is the paucity of studies that have assessed changes in networks over time and how these changes potentially affect HIV risk. One of the difficulties is following network members over time to determine if they have changed their behavior or their social contacts. Nevertheless, given the great uncertainties of life facing many IDUs, there are sure to be changes in their social networks that affect their risk behaviors, even over a short period of time. For example, since IDUs are involved in illicit behavior, the chance of arrest or incarceration is high and these effects multiply if we consider how arrest or incarceration affects not only the IDU but also the network structure (e.g. an IDU's injection partner(s) is arrested, thus disrupting the potential flow of drugs or the behavior of the group). Moreover, many IDUs move in and out of drug treatment in an effort to modulate, or eliminate, their drug use (Murphy et al., 1989). Curtis et al. (1995) found that networks of IDUs are often mobile as they are pulled or pushed from one neighborhood to another in search of drugs or as a result of police pressure; and that these movements lead potentially to the addition of new, possibly HIV infected, network members.

The few studies that have assessed the dynamics of IDU networks have demonstrated that change has a significant impact on HIV risk behaviors. Neaigus et al. (1995), utilizing dyadic data, determined that higher network turnover (subjects had known each other for a shorter period of time) was positively related to HIV infection. In a longitudinal examination of IDU networks in Baltimore, Latkin et al. (1995b) found that higher network density and larger network size predicted increased needle sharing at a 6 month follow-up. One plausible hypothesis is that larger and more dense networks offer greater opportunities for needle sharing. Nevertheless, these studies fail to measure whether actual changes in networks affect HIV risk; rather, they focus either on the duration of a particular social tie or on changes in risk behaviors.

Although substantially more research is needed to understand how network changes affect individual and group behaviors (Leenders, 1995; Suitor et al., 1997), the accumulating evidence points to a significant impact of network changes on HIV risk behaviors. This paper presents an exploratory analysis of whether IDU networks change over a brief period of time (approximately 3 months), and what variables are associated with these changes. It also investigates whether network-level changes have any effect on risky injection behaviors such as sharing needles injection paraphernalia after controlling for individual-level characteristics. The hypotheses guiding the analysis are that (1) 
IDU networks do change substantially even during a brief period of time due to the uncertain lifestyles of most IDUs (cf. Curtis et al., 1995) and that (2) changes in network structure have a significant impact on risky injection behavior since they affect the opportunities and circumstances surrounding drug use (Latkin et al., 1995a,b; Friedman, 1995).

\section{Data and methods}

The data used to test the hypotheses are from the drug injector risk networks and HIV transmission study, an exploratory study designed to collect data on the structure and dynamics of IDU risk networks in two large cities, Chicago and Washington, DC. Recruitment and data collection took place over a 9 month period in 1995 . The study collected epidemiological and ethnographic information, including precise network plotting of injection and sexual partner contacts, from a total of 123 IDUs recruited through a modified, chain-referral sampling approach consisting of several stages. During the initial stage, we used ethnographic methods such as participant observation, areal mapping and ground observation to outline the sociodemographic and cultural contours of several inner-city neighborhoods in Washington and Chicago (Carlson et al., 1994; Wiebel, 1990). After spending a period of time (from 1 to 2 months) in several neighborhoods and developing relationships with a number of ethnographic informants (Johnson, 1990), our ethnographers recruited IDUs who they contacted through community outreach, meetings with key members of neighborhoods (e.g. former IDUs), and by assisting at needle exchange sessions. ${ }^{1}$ Our sampling goal was to begin several chains of recruitment in diverse neighborhoods, and to target a similar number of representatives of sex and racial/ethnic groups (Carlson et al., 1994; Watters and Biernacki, 1989), so that multiple IDU networks would be represented. The sample was designed to include subjects from several points of the respective cities; subjects who represented broad demographic subgroups. For example, we were especially interested in young white and Hispanic IDUs, since HIV risk behaviors among these groups are poorly understood.

This paper focuses on the index subjects who were recruited independent of referral from other IDUs, but the measurement of several key variables was supplemented with data from interviews and contacts with non-index subjects (see below). The index subjects represented the beginning of several chains that led us into

\footnotetext{
${ }^{1}$ Our ethnographers had worked on previous projects in some of the neighborhoods, so they had established relationships with several key informants prior to the beginning of fieldwork.
}

a number of IDU networks. Due to funding limitations, we were unable to conduct structured interviews with each identified member of each network. Sixty-five index subjects were recruited who met the following inclusion criteria: (1) Injection of any psychoactive drug during the previous 30 days; (2) no participation in any drug abuse treatment program at the time of interview; (3) age 18 or older. We confirmed that index subjects were indeed injection drug users by looking for physical evidence of recent needle tracks and by using secondary sources obtained through ethnographic methods.

\subsection{Data collection procedures}

Index subjects took part in two structured interviews. The structured interviews included questions about sociodemographic characteristics, living arrangements, drug use, sharing needles and paraphernalia, needle and paraphernalia cleaning practices, and injection and sexual partners from the previous 30 days. The interview lasted about $1 \mathrm{~h}$ and all information was kept strictly confidential. A key component of the interview consisted of a network plotting exercise. Subjects were asked to identify other members of her or his network; that is, other individuals with whom they injected drugs or with whom they had sexual relations. They were also asked to estimate the interrelationships that existed among different potential members of their network. By actually plotting these various relationships, we were able to develop initial information on the size, density, and behavior of IDU networks (Latkin et al., 1995b). We then assessed the quality of this information with ethnographic data (see below).

After a 3 month period, we attempted to locate all index subjects for a follow-up interview. Out of a total of 65 index subjects interviewed at time 1, 55, or $85 \%$ were successfully located and interviewed at time 2 . By conducting a similar network plotting exercise during the follow-up interviews as during the intake interviews, we were able to determine whether particular networks had changed over a three month period. The ten index subjects who did not participate during the time 2 interview did not differ from those who did participate in terms of demographic characteristics, but they were slightly more likely to report recent homelessness and risky injection behavior.

The ethnographers in each city who were involved in recruitment also used a number of ethnographic methods to gather substantial supplemental information on individual subjects and IDU networks. In particular, each ethnographer spent a substantial period of time involved in participant observation among IDUs in the neighborhoods (Adler, 1990; Agar, 1980; Koester, 1994, 1995; Wiebel, 1990). They were able to establish their presence in the community well enough to conduct numerous informal, open-ended interviews, life history 
interviews, injection recall interviews, and direct observation of injection events (Koester, 1994). For example, informal interviews were conducted with each index subject, and with many other members of their IDU networks. During these interviews, the ethnographers developed network plots that identified injection and sexual ties among numerous members of the respective networks. Thus, we were able to investigate the validity and reliability of information provided by index subjects about network membership, size, density, and behavior. In situations where we found a discrepancy between an index subject's report and our ethnographic observations and interviews, we attempted to reconcile information by checking sources and reinterviewing participants. ${ }^{2}$

\subsection{Measurement of individual characteristics and network properties}

Sociodemographic characteristics were ascertained in a straightforward manner by asking subjects to self-classify themselves into various categories. Forty percent of the subjects were age 40 or older; $64 \%$ were male and $36 \%$ female; $47 \%$ were African-American, $33 \%$ white and $20 \%$ Hispanic; and 7\% self-reported HIV infection.

We wished to assess the effects of network characteristics on risky injection practices (hypothesis 2); therefore, it was important to control for the effects of individual-level characteristics in addition to sociodemographic variables that are associated with risky injection. Several studies have shown that there are certain non-injection related behaviors that increase the odds of IDU engagement in risky injection behaviors. For example, crack use among IDUs intensifies the level of injection risk behaviors such as sharing needles and paraphernalia (Booth et al., 1993; Chaisson et al., 1989; Edlin et al., 1992). Furthermore, sexual risk behavior is associated with injection risk behavior; a common hypothesis is that there are several levels of risk-taking among IDUs and those with a greater risk propensity will be involved in both sexual risk behaviors and injection risk behaviors (Rhodes and Stimson, 1994). Finally, homelessness is associated in several studies with risky drug using behav-

\footnotetext{
${ }^{2}$ Initially, we planned to code the ethnographic data in such a manner as to facilitate qualitative data analysis (Miles and Huberman, 1994). This would have allowed us to carefully assess the validity and reliability of the qualitative and quantitative methods that we gathered for this study. Unfortunately, funding limitations prevented us from coding the ethnographic data, so we could not conduct a full analysis. However, we did assess the data with multiple reviewers to identify themes, construct typologies, and assess individual observer presuppositions (Carey, 1993; Taylor and Bogdan, 1984). The themes that emerged were especially useful for interpreting the patterns found in the quantitative data. Moreover, the network plotting exercise that was conducted with multiple members of the networks during the initial data collection period and periodically thereafter (during informal and structured interviews) allowed us to validate index subjects' descriptions of network properties (e.g. density).
}

ior (Beardsley et al., 1992; Edlin et al., 1992; Lambert and Caces, 1995; Latkin et al., 1994; Sterk-Elifson and Sterk-Elifson, 1992).

We measured crack use by asking respondents whether they had used crack cocaine in the previous 30 days. Sexual risk behavior was measured by determining whether respondents had had sex with another injection drug user, or had multiple sex partners without consistent condom use, in the past 30 days. Homelessness was measured by asking respondents whether they had slept on the street or at a homeless shelter in the past 30 days. $^{3}$ Our individual-level outcome variable (hypothesis 2 above) is injection risk behavior measured during both the intake and follow-up interviews. Injection risk behavior includes sharing needles in the absence of bleach cleaning; sharing cookers, cottons, or rinse water; or frontloading or backloading (syringe-mediated drug sharing, Jose et al., 1993), in the past 30 days.

We also computed several network-level measures, including density (the proportion of injecting or sexual ties present in a network) and size (Wasserman and Faust, 1994), at both time 1 and time 2, to determine whether changes took place over the 3 month period studied. The average density was about 0.29 at time 1 and 0.33 at time 2 , while the average size was about 17 at time 10 and 16 at time 2 .

However, we were also interested in developing network-level measures that could be used to determine risk in the network. The first network measure developed was the percent of risky members in a network. A risky member is one who had engaged in sexual risk behaviors or injection risk behaviors in the previous 30 days. Sexual risk behavior and injection risk behavior are defined above. If any IDU from a network had engaged in any of these behaviors in the past 30 days, then she or he was identified as a risky network member, and, by aggregating responses by networks across the entire subject list interviewed in each network (index and non-index), a measure of the proportion of risky members in a network was developed. The mean and median were about $75 \%$.

The second network-level measure, network HIV status, merely identifies whether any network member self-reported positive HIV serostatus. The measure is a simple dichotomy that identifies positive HIV network status (at least one network member positive) versus negative status. It is important to remember that these positive members of a network were not necessarily included among the 55 respondents used in the analysis. Any member identified as HIV positive during the

\footnotetext{
${ }^{3}$ Research has shown that there are several other factors that affect risky injection behaviors, such as injection in shooting galleries, injection of speedballs (cocaine and heroin), prostitution and sexually transmitted disease infection (Booth et al., 1993; Battjes et al., 1994; Page, 1990). However, the IDUs who participated in our study reported few of these cofactors, so we focused on sociodemographics, crack use, risky sexual behavior and homelessness.
} 
intake interview, or during our ethnographic research, was included when we developed the network HIV status variable. However, this estimate is probably low, since we had to rely on self-reports, and could not obtain blood samples for testing. ${ }^{4}$

Like network density and network size, the above two network measures are static. Changes in these network-level variables, especially in density or size, fail to capture the true dynamics that occur in particular networks since, for example, size would be identical if two members of a specific network from time one left and two new members joined the network by time two. Unfortunately, there has been little research on the development of dynamic network measures (Leenders, 1995; Sanil et al., 1995; Suitor et al., 1997; Wasserman and Faust, 1994). Nonetheless, since one of the main goals of this paper was to examine network-level changes, we developed two heuristic measures that capture, in an elementary way, how IDU networks might change over a brief period of time. These measures, tentatively labeled network turnover, determine the proportional movement of individuals into and out of networks. Rather than one summary measure of network turnover, we developed two indicators of movement since members moving into a network might have different implications than members moving out of a network. Network turnover-in measures the proportion of new members of a network at time two, while network turnover-out measures the proportion of network members who left between time one and time two. Since these measures could be affected substantially by network size (e.g. larger networks might, on average, lose a smaller proportion of members simply due to their size), each was weighted by the natural logarithm of network size. ${ }^{5}$ These two measures, along with size and density at time 1 and time 2 , were the outcome variables in our analysis of whether networks change over a short period of time (hypothesis 1). Furthermore, our exploratory analysis of injection risk behaviors included these network-level variables to de-
Table 1

Distribution of individual and network characteristics $(n=55)$

\begin{tabular}{|c|c|c|c|}
\hline & Percent & Mean & S.D. \\
\hline \multicolumn{4}{|l|}{ Individual characteristics } \\
\hline \multicolumn{4}{|l|}{ Age } \\
\hline $18-39$ & 62 & & \\
\hline 40 and older & 38 & & \\
\hline \multicolumn{4}{|l|}{ Sex } \\
\hline Male & 64 & & \\
\hline Female & 36 & & \\
\hline \multicolumn{4}{|l|}{ Race/Ethnicity } \\
\hline African-American & 47 & & \\
\hline White & 33 & & \\
\hline Hispanic & 19 & & \\
\hline Homeless (past 30 days) & 25 & & \\
\hline Sexual risk behavior (past 30 days) ${ }^{a}$ & 55 & & \\
\hline Crack use (past 30 days) & 53 & & \\
\hline HIV Status ( $\%$ positive) & 7 & & \\
\hline \multicolumn{4}{|l|}{$\begin{array}{l}\text { Injection Risk Behavior (past } 30 \\
\text { days) }^{\mathrm{b}}\end{array}$} \\
\hline Time 1 & 60 & & \\
\hline Time 2 & 58 & & \\
\hline \multicolumn{4}{|l|}{ Network Characteristics } \\
\hline \multicolumn{4}{|l|}{ Network Size } \\
\hline Time 1 & & 17.4 & 17.8 \\
\hline Time 2 & & 15.8 & 14.5 \\
\hline \multicolumn{4}{|l|}{ Network Density } \\
\hline Time 1 & & 29.2 & 29.1 \\
\hline Time 2 & & 33.3 & 35.4 \\
\hline Percent of risky members ${ }^{\mathrm{c}}$ & & 75.4 & 27.1 \\
\hline Network Turnover-In ${ }^{\mathrm{d}}$ & & 3.1 & 2.9 \\
\hline Network Turnover-Outs ${ }^{\mathrm{e}}$ & & 5.6 & 6.7 \\
\hline Network HIV Status (\% positive $)^{\mathrm{f}}$ & 20 & & \\
\hline
\end{tabular}

${ }^{a}$ Includes sex with an injection drug user, or having multiple sexual partners without consistent condom use.

${ }^{b}$ Includes sharing needles in the absence of bleach cleaning, or sharing cookers, cottons, rinse water, or front/backloading.

${ }^{\mathrm{c}}$ Proportion of members within an identified network who reported engaging in sexual or injection risk behaviors in the past 30 days. d The proportion of new members entering the network at Time 2, weighted by the size of the network.

e The proportion of members leaving the network at Time 2, weighted by the size of the network.

${ }^{\mathrm{f}}$ At least one self-reported HIV-positive person is a member of the network.

\footnotetext{
${ }^{4}$ As mentioned in footnote 2, we attempted, where possible, to validate reports of network characteristics by index subjects with information from other network members (either through structured interviews or ethnographic interviews and observations). Given that we had substantial supplemental information from other interviews and from our ethnographic data (which was collected continuously throughout the study), we think our measures of network properties are well grounded and valid (cf. Latkin et al., 1995b).

${ }^{5}$ To make the weights proportional to network size, the inverse of size at time 1 (logged) was used. Transposing time 1 size (logged) and time 2 size (logged) does not change the results of the analysis. Natural logarithms were used since network size is highly skewed. The final formulae for the network turnover measures are therefore:
}

Network Turnover In: $\frac{\text { Number of new members at Time } 2}{\ln (\text { Size Time } 2)} \times 1 / \ln ($ Size Time 1$)$

Network Turnover Out: $\frac{\text { Number of members leaving by Time } 2}{\ln (\text { Size Time } 2)} \times 1 / \ln ($ Size Time 1$)$

Although these are new measures based on empirical criteria, a preliminary sensitivity analysis suggests that they provide essential information about changes in networks that is not captured well by traditional network measures. Moreover, other network change measures are based, for various statistical reasons, on three or more longitudinal points, and require that the node size be fixed (see Sanil et al., 1995). 
Table 2

Changes in IDU networks over a 3 month period, by individual and network risk charaeteristies

\begin{tabular}{|c|c|c|c|c|c|c|}
\hline & \multicolumn{2}{|c|}{ Network size } & \multicolumn{2}{|c|}{ Network density } & \multirow[t]{2}{*}{ Network turnover-in } & \multirow[t]{2}{*}{ Network turnover-out } \\
\hline & Time 1 & Time 2 & Time 1 & Time 2 & & \\
\hline Total & 17.4 & 15.8 & 29.2 & 33.3 & 3.1 & 5.6 \\
\hline \multicolumn{7}{|l|}{ Individual characteristics } \\
\hline \multicolumn{7}{|l|}{ Age } \\
\hline $18-39$ & 13.9 & 13.4 & 26.2 & 32.9 & 2.9 & 4.1 \\
\hline 40 and older & 23.0 & $19.6 \dagger$ & 34.0 & 34.1 & 3.4 & 8.1 \\
\hline \multicolumn{7}{|l|}{ Sex } \\
\hline Male & 18.7 & 17.4 & 23.5 & 24.9 & 3.4 & 5.7 \\
\hline Female & 15.1 & 12.9 & $39.2^{*}$ & $48.0^{* \dagger}$ & 2.5 & 5.5 \\
\hline \multicolumn{7}{|l|}{ Race/Ethnicity } \\
\hline African-American & 24.3 & $20.5 \dagger$ & 30.0 & 28.6 & 3.4 & 8.0 \\
\hline White & 11.1 & 11.7 & 30.8 & 29.9 & 2.7 & 2.8 \\
\hline Hispanic & 10.6 & 10.7 & 25.7 & 54.5 & 2.8 & 4.6 \\
\hline \multicolumn{7}{|l|}{ Homeless } \\
\hline No & 12.5 & 12.6 & 32.6 & 35.7 & 2.5 & 3.4 \\
\hline Yes & 31.6 & 25.1 & 19.3 & 26.3 & $4.6^{*}$ & $12.3^{*}$ \\
\hline \multicolumn{7}{|l|}{ Sexual Risk Behavior } \\
\hline No & 14.9 & 13.8 & 28.0 & 35.8 & 2.6 & 4.7 \\
\hline Yes & 19.3 & 17.5 & 30.2 & 31.3 & 3.5 & 6.3 \\
\hline \multicolumn{7}{|l|}{ Crack Use } \\
\hline No & 21.5 & $18.4 \dagger$ & 23.5 & 31.9 & 3.2 & 7.0 \\
\hline Yes & 12.7 & 12.8 & $35.6^{*}$ & 34.9 & 2.9 & $4.1^{*}$ \\
\hline \multicolumn{7}{|c|}{ Network risk characteristics } \\
\hline \multicolumn{7}{|l|}{ Percent risky members } \\
\hline Less than $75 \%$ & 12.1 & 13.1 & 29.1 & 29.9 & 2.4 & 2.2 \\
\hline $75 \%$ or more & 21.7 & $18.0 \dagger$ & 29.2 & 36.2 & $3.6^{*}$ & $8.5^{*}$ \\
\hline \multicolumn{7}{|l|}{ Network HIV Status } \\
\hline Negative & 12.8 & $13.4 \dagger$ & 21.2 & 27.2 & 2.4 & 3.1 \\
\hline Positive & 18.5 & 16.4 & 31.2 & 34.9 & 3.2 & 6.3 \\
\hline
\end{tabular}

See Table 1 for definitions of variables.

* Difference between subgroups is significant at $P<0.05$ level (e.g. comparing males and females on network size at Time 1).

$\dagger$ Difference over time within subgroup is significant at $P<0.05$ level (e.g. comparing network size among females at Time 1 and Time 2 ).

termine whether network changes affect risky injection practices (hypothesis 2).

\section{Results}

Since this analysis was exploratory in nature, we relied on cross-classifications of relevant variables to determine the magnitude of change across networks by individual and network attributes. In order to determine whether there were differences across individuals or groups, we estimated nonparametric statistics to assess significance. Both the Wilcoxon rank sum test and Savage test were used when comparisons were made between two groups (e.g. males versus females), and the Kruskal-Wallis test and $k$-sample Savage test were used when comparisons were made among three or more groups. In order to test for across-time changes among the groups (e.g. does network size change significantly among male IDUs?), we used a Wilcoxon signed rank test (Conover, 1980; Hollander and Wolfe, 1973).
Before moving to this analysis, Table 1 presents the distribution of individual and network characteristics among the 55 IDUs who comprise the sample. As mentioned above, almost two-thirds of participants were male, and almost half were African-American. About one-quarter reported homelessness in the previous 30 days. Fifty-five percent reported sexual risk behaviors in the previous 30 days, 53\% reported crack use in the past 30 days and about $60 \%$ reported injection risk behaviors in the previous 30 days at time one and time two. The average network size was about 17 and the density was about 30 (i.e. proportion of sexual or injection ties in a network multiplied by 100). Seven percent, or four respondents, self-reported HIV positive status. ${ }^{6}$ About $20 \%$ of the networks had at least one member self-report HIV positive status. The average

\footnotetext{
${ }^{6}$ Since so few respondents self-identified as HIV positive, we do not use this information in later analyses. However, we are not thus implying that positive HIV status has no effect on either risk behaviors or movement into or out of IDU networks.
} 
percentage of risky members in a network was about $75 \%$. Finally, network turnover-in averaged about three, while network turnover-out averaged almost six. Although there is no intuitive interpretation of these latter two measures, they are directly comparable, and suggest much more movement out of networks than into networks.

Table 2 provides the cross-classification of individual and network characteristics by the network change variables. As mentioned above, we rely on nonparametric significance tests to determine differences across subgroups (significant results identified by asterisks), and changes over time (significant results identified by daggers). The results indicate few significant differences, and suggest that hypothesis one is only nominally supported. For example, network size does not change much over the time period studied. Among older IDUs and African-American IDUs, and in those networks with a higher proportion of risky members, there is a small, but significant, decrease in network size. Network density, however, increases significantly among female IDUs. Coupled with the finding that female IDUs tend to reside in more dense networks than male IDUs, this suggests that male and female IDUs either are part of networks made up of different compositions, or that female IDUs reside in more intimate networks than male IDUs. This latter interpretation is supported by research that shows that female IDUs tend to inject with male sexual partners, while male IDUs are more likely to inject with friends and acquaintances (Bernard, 1993; Booth, 1995; Maher et al., 1996; Su and Gerstein, 1995). Since network density among female IDUs increased over the 3 month period, perhaps greater intimacy develops if a network structure stays intact.

Turning to the network change measures designed for this study, we found, once again, few significant differences among the sociodemographic and behavioral subgroups. Crack users resided in networks that lost fewer members over the 3 month period. This is somewhat surprising given that past research has suggested that crack-using IDUs appear more disorganized and more risky than non-crack-using IDUs (e.g. Booth et al., 1993; Edlin et al., 1992). Thus, one might reasonably suspect that crack users would reside in more tumultuous networks; however, this was not the case among our respondents.

Homeless IDUs reported substantially greater movement of members into and out of their networks. This supports the position that homelessness among IDUs is associated with a more turbulent lifestyle, and suggests that this turbulence is identified well by movement into and out of social networks (Beardsley et al., 1992; Latkin et al., 1994).
Finally, it is not surprising that networks comprised of a greater proportion of risky members manifested greater movement over time than less risky networks. Risky networks may present risks that are recognizable to IDUs. Therefore, members are more likely to leave these networks. The lost members could represent lost capital for the network (e.g. fewer aggregate resources to purchase drugs or obtain syringes), hence the riskier networks require new members. Moreover, the riskiness of a network may represent some other unmeasured variable that is related to greater movement into or out of a network. For example, less stable networks might be comprised of members who have less access to the resources needed to obtain drugs and injection equipment. The continuous search for steady drug supplies, and the illegal nature of this enterprise, forces movement among IDUs and produces more rapid dissolution of old networks and more frequent formation of new networks (Curtis et al., 1995; Pach, 1995). The chaotic nature of these networks may affect the riskiness of their members, since uncertain supplies promote more needle sharing, and more sharing of cookers, cottons, and other paraphernalia. This interpretation is tenable given the association shown between homelessness and network movement if we assume that the presence of homeless IDUs in a network is one indicator of few resources. In order to examine this explanation in more detail, it is necessary to examine the effect of network characteristics on individual risk behaviors. Our next stage in the analysis does this by testing hypothesis 2 .

Table 3 presents the results of a two-step exploratory analysis designed to test the plausibility of our second hypothesis. In the first step we assessed bivariate cross-classifications of individual and network characteristics by injection risk behavior during the 30 days prior to the follow-up interview. The results are shown as bivariate odds ratios in Table 3 (second column). An odds ratio significantly greater than one indicates a positive association, while an odds ratio between zero and one indicates a negative association. Ninety-five percent confidence intervals are provided in order to examine the significance and potential variability of the odds ratio (Greenland and Robins, 1985). These results indicate that sexual risk behavior at time 1, injection risk behavior at time one, and network turnover-in from time 1 to time 2 significantly increased the odds of injection risk behavior at time 2 . Those who reported sexual risk behavior were about four times as likely as those who did not report sexual risk behavior to engage in injection risk behavior. Moreover, each incremental increase in new members coming into a network increased the odds injection risk behavior by about $50 \%$. The remaining variables had no significant effect on injection risk behavior. 
In order to examine the hypothesis further, we estimated a logistic regression model designed to predict injection risk behavior at time two (Hosmer and Lemeshow, 1989). The results are provided in the third column of Table 3. Since injection risk behavior at time one is included in the model, we are measuring changes in this behavior (see Plewis, 1985). The same three variables remain as significant predictors of injection risk behavior: Injection risk behavior at time 1, sexual risk behavior at time 1 , and network turnover-in. Once we control for the effects of other variables, sexual risk behavior becomes a powerful predictor of injection risk behavior. Irrespective of how they are viewed, these two behaviors are strongly related among the IDUs in our study. Moreover, a higher proportion of new members entering a network is associated with a significant increase in the odds of injection risk behavior, even after controlling for several sociodemographic and behavioral variables.

\section{Discussion}

It is clear, based on this exploratory analysis, that IDU networks change, even over a brief period of time, and that these changes have an important impact on risky injection behaviors. Although we cannot

\section{Table 3}

Odds of engaging in risky injection behavior in the past 30 days, by individual and network characteristics

\begin{tabular}{|c|c|c|}
\hline & \multicolumn{2}{|c|}{ Injection risk behavior-Time 2} \\
\hline & $\begin{array}{l}\text { Bivariate odds } \\
\text { ratio }\end{array}$ & $\begin{array}{l}\text { Multivariate } \\
\text { odds ratio }\end{array}$ \\
\hline \multicolumn{3}{|l|}{ Individual characteristics } \\
\hline Age & $0.9(0.3,2.8)$ & $0.8(0.1,7.9)$ \\
\hline Sex & $0.8(0.3,2.5)$ & $1.5(0.1,18.5)$ \\
\hline Race/Ethnicity ${ }^{\mathrm{a}}$ & $0.9(0.3,2.8)$ & $1.8(0.1,37.0)$ \\
\hline Homeless & $1.5(0.4,4-9)$ & $0.5(0.1,12.1)$ \\
\hline Sexual risk behavior & $4.1(1.3,12.9)$ & $45.4(1.2,624.2)$ \\
\hline Crack Use & $0.8(0.3,2.3)$ & $0.7(0.1,7.2)$ \\
\hline $\begin{array}{l}\text { Injection risk behavior, } \\
\text { Time } 1\end{array}$ & $6.7(2.0,22.2)$ & $45.4(1.7,64.7)$ \\
\hline \multicolumn{3}{|l|}{ Network Characteristics } \\
\hline Size, Time 1 & $1.0(0.9,1.1)$ & $0.9(0.7,1.1)$ \\
\hline Density, Time 1 & $0.1(<0.1,1.3)$ & $0.1(<0.1,28.2)$ \\
\hline Percent of risky members & $1.5(0.5,4-7)$ & $0.1(<0.1,2.4)$ \\
\hline Network HIV Status & $0.8(0.2,3.1)$ & $0.2(<0.1,5.4)$ \\
\hline Network Turnover-In & $1.5(1.2,2.0)$ & $6.0(1.2,28.7)$ \\
\hline Network Turnover-Out & $1.0(0.9,1.1)$ & $0.7(0.5,1.2)$ \\
\hline
\end{tabular}

These results are based on logistic regression models. 95\% confidence intervals appear in parentheses. See Table 1 for definitions of variables.

aAfrican-Americans compared to whites and Hispanics. attribute causality to our results, they agree with previous studies (e.g. Curtis et al., 1995; Latkin et al., 1995b; Neaigus et al., 1995) in showing that changes in networks may promote a more tumultuous atmosphere for the conduct of illegal behaviors such as injection drug use, and appear to increase the chances of risky injection behavior. The significant association between network turnover-in and changes in risky injection behavior suggests that allowing a greater proportion of new members into a network increases risks at the individual-level. Our quantitative data and models provide little information about why this occurs, but our ethnographic research, especially data from participant observation, informal interviews, and direct observations of injection events, uncovered a useful lens through which to view the pattern of relationships.

In virtually all the IDU networks we observed, as in many types of social networks, relationships were based primarily on various exchanges of tangible and intangible goods and services (cf. Gregory, 1982). The principal 'goods' in these exchange relationships were drugs, money, and injection paraphernalia. However, there was a continuum of access to these goods: some IDUs had a stable source of income and therefore a relatively undisturbed source of drugs and injection equipment. Since they could purchase their own drug supplies, there was little need to share injection equipment, even though they were just as likely as others to inject in groups. Many other IDUs, however, had to pool resources in order to purchase drugs, syringes, and other equipment. Our ethnographic work suggested that those networks comprised of IDUs with a more stable resource base were also less likely to accept new members, and had fewer members leaving due to arrest, overdose, or other unforeseen circumstances. On the other hand, a less stable resource base among network members was associated with a greater propensity to move around in search of what to these IDUs were scarce resources. This interpretation is supported, in part, by the significant association between homelessness and network turnover (Table 2).

Moreover, the range and rate of exchanges among network members were not consistent. For example, IDUs in more chaotic networks almost never had money to contribute to the purchase of drugs, and they were often forced to inject with syringes used by other network members (Bourgois, 1995). They often moved around to different groups, and they were very willing to accept new members into their networks with the hope that a new source of money or drugs would thus be available. These dynamics, especially when they occurred among groups of IDUs with a weak resource base, tended to feed back and magnify risky injection 
behaviors. The result was a continuous increase, or uncertain fluctuation, in risk behaviors. We suspect that this pattern of resource access may explain much of the variation in risk behaviors among sociodemographic groups. For example, various studies have shown that younger IDUs, African-American IDUs, and homeless IDUs tend to be more involved in risky injection behaviors (e.g. Battjes et al., 1994; Beardsley et al., 1992). One potential reason for this variation is that these groups often have a more tenuous resource base than other groups, such as older IDUs or white IDUs. A final point about this line of reasoning is that resource access should be conceptualized and measured at the network-level. As we found, homelessness at the individual-level may be indicative of a less stable network (Table 2), but it does not predict changes in risk behaviors (Table 3). Thus, one should investigate the actual movement of the network to predict changes in risk behaviors, and determine whether this movement suggests a lack of resource access at the network-level.

Obviously, more research is needed to further explore this hypothesis of resource access. Our data are not well suited for measuring access to resources, especially at the network-level, or similar variables that might capture the wealth or poverty of particular IDU networks; nevertheless, a focus on access to resources provides a promising theoretical path for understanding variations in risk behaviors among IDUs.

\section{Conclusion}

This study was designed to explore whether IDU networks change over a brief period of time, assess whether individual and network characteristics are associated with these changes, and investigate how network changes affect the likelihood of HIV risk behaviors among IDUs. At the aggregate level, we found little change in IDU networks. Network size and density changed little over a 3 month period. However, we determined that network variables designed specifically to track individuals in and out of the networks do show substantial changes in networks, even over a brief time period. This result should not be surprising given how illegal activities dominate many IDU lives (Agar, 1973; Curtis et al., 1995). Although sociodemographic variables do a poor job of predicting these network changes, it is important to carefully consider change at the network level, especially since these changes may predict behaviors that put IDUs at high risk for HIV infection.

In particular, we found that greater movement of members into a network was significantly associated with more risky injection behavior over the 3 month period studied. Although our quantitative data are not rich enough to fully explain this result, we suggest that much of this effect is due to the resources available to IDU networks. Our ethnographic work showed a substantial continuum of monetary and personal resources available to IDUs and their networks. Members of networks with few resources had to move around much more in order to secure drug supplies, syringes, and places to inject. Thus, it is not surprising that they were also forced to take substantial risks, such as sharing needles and other paraphernalia.

This developing theoretical explanation of our results requires significantly more research since there are several limitations that make our analysis tentative. First, our sample size was small, and was drawn from only two inner-city areas (however, it included IDUs from several neighborhoods in each city). Second, we were able to follow the IDUs for only a brief period of time; a more robust test of the structural dynamics of networks and an explanation that involves access to resources require more data gathered over a longer period of time. Third, most of our measures relied on the index subjects' reports derived from structured interviews. Fully linked network data are needed to adequately assess most network measures. Thus, our measures of network properties are limited. Fourth, the ten index subjects who did not participate in the follow-up interview were more likely to be risky injectors, so we may be underestimating some of the effects in the model. Finally, we did not gather sufficient information about access to resources, but we now realize that this type of information is crucial if we are to uncover the precise sociodynamic mechanisms that underlie IDU risk behaviors.

\section{Acknowledgements}

An earlier draft of this paper was presented at the 1996 International Sunbelt Social Network Conference, Charleston, SC. We would like to thank Felicia Gray, Richard Rothenberg, Dean Gerstein, and several anonymous reviewers for their useful suggestions. We also appreciate the work of the following staff who were responsible for data collection and management: Todd Pierce, Esther Barkley, Arlin Ramsey, Julie Ingels, Rob van Veggel, Chris Unfred, and Ellen Kaplowitz.

\section{References}

Adler, P., 1990. Ethnographic research on hidden populations: Penetrating the drug world. In: Lambert, E.Y. (Ed.), The Collection and of Data from Hidden Populations. NIDA Research Monograph No. 98. NIDA, Rockville, MD pp. 96112. 
Agar, M., 1973. Ripping and Running: A Formal Ethnographic Study of Urban Heroin Addicts. Seminar Press, New York.

Agar, M., 1980. The Professional Stranger: An Informal Introduction to Ethnography. Academic Press, New York.

AIDS Surveillance and Epidemiology Programs., 1994. AIDS Chicago: Fourth quarter, 1994 AIDS Surveillance Report. Department of Public Health, Chicago.

Battjes, R.J., Pickens, R.W., Haverkos, H.W., Sloboda, Z., 1994. HIV risk factors among injecting drug users in five U. S. cities. AIDS 8, 681-687.

Beardsley, M., Clatts, M.C., Deren, S., Davis, W.R., Tortu, S., 1992. Homelessness and HIV-risk behaviors in a sample of New York City drug injectors. AIDS Public Policy J. 7, 162-169.

Bernard, M.A., 1993. Needle sharing in context: Patterns of sharing among men and women injectors and HIV risks. Addiction 88, $805-812$.

Blower, S., Medley, G., 1992. Epidemiology, HIV and drugs: Mathematical models and data. Br. J. Addiction 87, 371-379.

Booth, R.E., 1995. Gender differences in high risk sex behaviors among heterosexual drug injectors and crack smokers. Am. J. Drug Alcohol Abuse 21, 419-432.

Booth, R.E., Watters, J.K., Chitwood, D.D., 1993. HIV risk-related sex behaviors among injection drug users, crack users, and injection drug users who smoke crack. Am. J. Public Health 83, 1144-1148.

Bourgois, P., 1995. Participant observation study of indirect paraphernalia sharing/HIV risk in a network of heroin injectors. Final Report to the Community Research Branch, National Institute on Drug Abuse.

Carey, J.W., 1993. Linking qualitative and quantitative methods: Integrating cultural factors in public health. Qualitative Health Res. 3, 298-318.

Carlson, R.G., Wang, J., Siegal, H.A., Falck, R.S., Guo, J., 1994. An ethnographic approach to targeted sampling: Problems and solutions in AIDS prevention research among injection drug and crack-cocaine users. Human Organization 53, 279-286.

Chaisson, R.E., Bacchetti, P., Osmond, D., Brodie, B., Sande, M.A., Moss, A.R., 1989. Cocaine use and HIV infection in intravenous drug users in San Francisco. J. Am. Med. Assoc. 261, 561-565.

Conover, W.J., 1980. Practical Nonparametric Statistics, 2nd Edition. John Wiley and Sons, New York.

Curtis, R., Friedman, S.R., Neaigus, A., Jose, B., Goldstein, M., Ildefonso, G., 1995. Street-level drug markets: Network structure and HIV risk. Social Networks 17, 229-250.

Division of HIV/AIDS Epidemiology, 1994. AIDS Surveillance Update. Agency for HIV/AIDS, Commission of Public Health, Washington, DC.

Edlin, B.R., Irwin, K.L., Ludwig, D.D., et al., 1992. High-risk sex behavior among young streetrecruited crack cocaine smokers in three american cities: An interim report. J. Psychoac. Drugs 24, $363-371$.

Friedman, S.R., 1995. Promising social network research results and suggestions for a research agenda. In: Needle, R.H., Coyle, S.L., Genser, S.G., Trotter R.T. (Eds.), Social Networks, Drug Abuse and HIV Transmission, pp. 196-215NIDA Research Monograph No.151. NIDA, Rockville, MD.

Gibson, D.R., Catania, J.A., Peterson, J.L., 1991. Theoretical background. In: Sorenson, J.L., Wermuth, L.A., Gibson, D.R., Choi, K.H., Guydish, J.R., Batki, S.L. (Eds.), Preventing AIDS in Drug Users and Their Sexual Partners, pp. 62-74. Guildford Press, New York.

Greenland, S., Robins, J.M., 1985. Estimation of a common effect parameter from sparse follow-up data. Biometrics 41, 55-68.

Gregory, C., 1982. Gifts and Commodities. Academic Press, New York.

Hanson, B., Beschner, G., Walter, J.M., Bovelle, E., 1985. Life With Heroin. Lexington Books, Lexington, MA.
Hollander, M., Wolfe, D.A., 1973. Nonparametric Statistical Methods. John Wiley and Sons, New York.

Hosmer, D.W., Lemeshow, S., 1989. Applied Logistic Regression. John Wiley and Sons, New York.

Inciardi, J., Page, J.B., 1991. Drug sharing among intravenous drug users. AIDS 5, 772-773.

Johnson, J.C., 1990. Selecting Ethnographic Informants. Sage, Newbury Park, CA.

Jose, B., Friedman, S.R., Neaigus, A., Curtis, R., Grund, J.P., Goldstein, M.F., Ward, T.P., Des Jarlais, D.C., 1993. Syringe-mediated drug-sharing (backloading): A new risk factor for HIV among injecting drug users. AIDS 7, 1653-1660.

Klovdahl, A.S., Potterat, J.J., Woodhouse, D.E., Muth, J.B., Muth, S.Q., Darrow, W.W., 1994. Social networks and infectious disease: The Colorado Springs study. Soc. Sci. Med. 38, 79-88.

Koester, S.K., 1994. The context of risk: Ethnographic contributions to the study of drug use and HIV risk. In: Battjes, R.J., Sloboda, Z., Grace, W.C. (Eds.), The Context of HIV Risk Among Drug Users and Their Sexual Partners, NIDA Research Monograph No. 143. NIDA, Rockville, MD, pp. 202-217.

Koester, S., 1995. Applying the methodology of participant obsewation to the study of injection-related HIV risks. In: Lambert, E.Y., Ashem, R.S., Needle, R.H. (Eds.) Qualitative Methods in Drug Abuse and HIV Research, NIDA Research Monograph No. 157. NIDA, Rockville, MD, pp. 84-99.

Lambert, E.Y., Caces, M.F., 1995. Correlates of drug abuse among homeless and transient people in the Washington, DC, metropolitan area in 1991. Public Health Reports 110, 455-461.

Latkin, C., Mandell, W., Vlahov, D., Oziemtowska, M., Knowlton, A., Celentano, D., 1994. My place, your place, and no place: Behavior settings as a risk factor for HIV-related injection practices in Baltimore. Maryland. Am. J. Community Psychol. 22, 415-430.

Latkin, C., Mandell, W., Oziemkowska, M., Celentano, D., Vlahov, D., Ensminger, M., Knowlton, A., 1995a. Using social network analysis to study patterns of drug use among urban drug users at high risk for HIV/AIDS. Drug Alcohol Depend. 38, 1-9.

Latkin, C., Mandell, W., Vlahov, D., Knowlton, A., Oziemkowska, M., Celentano, D., 1995b. Personal network characteristics as antecedents to needle-sharing and shooting gallery attendance. Social Networks 17, 219-228.

Laumann, E.O., Gagnon, J.H., Michael, R.T., Michaels, S., 1994. The Social Organization of Sexuality. University of Chicago Press, Chicago.

Leenders, R.Th.A.J., 1995. Models for network dynamics: A markovian framework. J. Math. Sociol. 20, 1-21.

MacQueen, K.M., 1994. The epidemiology of HIV transmission: Trends, structure, and dynamics. Ann. Rev. Anthropol. 23, 509526.

Magura, S., Grossman, J.I., Lipton, D.S., Qudsia, S., Shapiro, J., Marion, I., Weisenfeld, L., Amana, K.R., Koger, J., 1991. Determinants of needle sharing among intravenous drug users. Am. J. Public Health 79, 459-462.

Maher, L., Dunlap, E., Johnson, B.D., Hamid, A., 1996. Gender, power, and alternative living arrangements in the inner-city crack culture. J. Res. Crime Delinquency 33, 181-205.

Miles, M.B., Huberman, A.M., 1994. Qualitative Data Analysis: A Sourcebook of New Methods. Sage, Thousand Oaks, CA.

Morris, M., 1993. Epidemiology and social networks: Modeling structured diffusion. Sociolog. Methods Res. 22, 99-126.

Murphy, S., Reinarman, C., Waldorf, D., 1989. An 11-year follow-up of a network of cocaine users. Br. J. Addiction 84, 427-436.

Neaigus, A., Friedman, S.R., Curtis, R., Des Jarlais, D.C., Furst, R.T., Jose, B., Mota, P., Stepherson, B., Sufian, M., Ward, T., Wright, J.W., 1994. The relevance of drug social and risk networks for understanding and preventing HIV infection. Soc. Sci. Med. 38, 67-78. 
Neaigus, A., Friedman, S.R., Goldstein, M., Ildefonso, G., Curtis, R., Jose, B., 1995. Using dyadic data for a network analysis of HIV infection and risk behaviors among injecting drug users. In: Needle, R.H., Coyle, S.L., Genser, S.G., Trotter, R.T. (Eds.), Social Networks, Drug Abuse, and HIV Transmission, pp. 20-36. NIDA Research Monograph No. 151. NIDA, Rockville, MD.

Nyamathi, A., Stein, J.A., Brecht, M.L., 1995. Psychosocial predictors of AIDS risk behavior and drug use behavior in homeless and drug addicted women of colon. Health Psychol. 14, 265-273.

Pach, A., 1995. Social exchange and HIV risk in injection drug networks in Chicago. Paper presented at the 94th Ann. meeting of the American Anthropological Association, November.

Page, J.B., 1990. Shooting scenarios and risk of HIV-1 infection. Am. Behav. Scientist 33, 478-490.

Petraitis, J., Flay, B.R., Miller, T.Q., 1995. Reviewing theories of adolescent substance use: Organizing pieces in the puzzle. Psycholog. Bull. 117, 67-86.

Plewis, I., 1985. Analysing Change: Measurement and Exploration Using Longitudinal Data. John Wiley and Sons, Chichester.

Rhodes, T., Stimson, G.V., 1994. What is the relationship between drug taking and sexual risk? Social relations and social research. Sociol. Health Illness 16, 210-228.

Rothenberg, R.B., Woodhouse, D.E., Potterat, J.J., Muth, S.Q., Darrow, W.W. and Klovdahl, A.S., 1995. Social networks in disease transmission: The Colorado Springs study. In: Needle, R.H., Coyle, S.L. Genser, S.G., Trotter, R.T. (Eds.), Social Networks, Drug Abuse, and HIV Transmission, pp. 3-19. NIDA Research Monograph No.151. NIDA, Rockville, MD.
Sanil, A., Banks, D., Carley, K., 1995. Models for evolving fixed node networks: Model fitting and model testing. Social Networks $17,65-81$.

Sterk-Elifson, C., Sterk-Elifson, K.W., 1992. Someone to count on: Homeless, male drug users and their friendship relations. Urban Anthropol. 21, 235-251.

Su, S.S., Gerstein, D.R., 1995. Understanding the exposure to HIV risks among female injection drug users: A social network approach. Paper presented at the 123rd annual meeting of the American Public Health Association, San Diego, CA.

Suitor, J.J., Wellman, B., Morgan, D.L., 1997. It's about time: How, why, and when networks change. Social Networks 19, 1-7.

Taylor, S.J., Bogdan, R., 1984. Introduction to Qualitative Research Methods: The Search for Meanings. John Wiley and Sons, New York.

Trotter, R.T., Baldwin, J.A., Bowen, A.M., 1995. Network structure and proxy measures of HIV, drug and incarceration risks for active drug users. Connections 18, 89-104.

Wallace, R., 1991. Traveling waves of HIV infection on a low dimensional socio-geographic network. Soc. Sci. Med. 32, 847852.

Wasserman, S., Faust, K., 1994. Social Network Analysis: Methods and Applications. Cambridge University Press, Cambridge.

Watters, J.K., Biernacki, P., 1989. Targeted sampling: Options for the study of hidden populations. Social Problems 36, 416-430.

Wiebel, W.W., 1990. Identifying and gaining access to hidden populations. In: Lambert, E.Y. (Ed.), The Collection and Interpretation of Data from Hidden Populations, 4-13. NIDA Research Monograph No. 98. NIDA, Rockville, MD. 